The author wishes to express his thanks to the American Cyanamid Company, New York, for a sample of thiuret hydrochloride.

1. Vöckel, C. Ann. 43 (1842) 74.

2. Klason, P. J. prakt. Chem. [2] 38 (1888) 366.

3. Hantzsch, A. and Wolvekamp, M. Ann. 331 (1904) 265.

4. Söderbäck, E. Ann. 419 (1919) 217.

5. Söderbäck, E. Ann. 465 (1928) 184.

6. Preisler, P. W. and Bateman, M. M. J. Am. Chem. Soc. 69 (1947) 2632.

7. Dithiobiuret, Technical Data Sheet, American Cyanamid Company, New York, 1947.

8. Foss, O. and Tjomsland, O. Acta Chem. Scand. 10 (1956) 869.

Received June 13, 1956.

Kinetics of the Heterogeneous Reaction of Calcium Bicarbonate Formation, with Special Reference to Copper Ion Inhibition

0. ERGA and S. G. TER JESEN

Chemical Engineering Laboratory, Technical University of Norway, Trondheim, Norway

The system $\mathrm{CaCO}_{3}(\mathrm{~s})-\mathrm{CO}_{2}(\mathrm{~g})-\mathrm{H}_{2} \mathrm{O}_{(1)}$ is 1 of considerable geological, physiological and technical importance. The reaction between solid calcium carbonate and aqueous carbon dioxide has therefore been discussed extensively in literature ${ }^{1}$. However, the published papers deal mainly with the thermodynamics of the reaction whereas the kinetic aspects seem to have been largely neglected.

Calcite of natural origin was used in the present investigation. When giving the ground material a repeated treatment with aqueous carbon dioxide, the reactivity of the calcite particles used for the experiment, did not change from one run to another. The experiments were carried out at $25^{\circ} \mathrm{C}$ in an agitated vessel made of stainless steel and designed to keep the solid particles well suspended in the liquid during the runs. The carbon dioxide-air mixture was blown into the suspension of calcite particles, and the reaction was followed by conductivity measurements.

The reaction was found to be strongly inhibited by very small amounts of copper

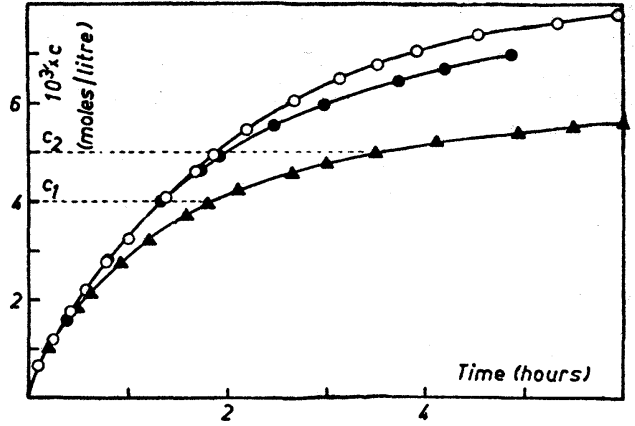

Fig. 1. Time-concentration curves showing the inhibiting effect of copper ions.

O: No active copper present
$: 2 \cdot 10^{-7}$ moles copper $/ l$
$\Delta: 10^{-5}$

ions. In Fig. 1 are shown the results of three runs, all carried out with $100 \mathrm{~g}$ of calcite suspended in 10 litres of distilled water. The particle size was $295-422 \mu$, corresponding to a surface area of approximately $125 \mathrm{~cm}^{2}$ per $\mathrm{g}^{2}$. The carbon dioxide pressure was $0.95 \mathrm{~atm}$. In the first experiment traces of copper inevitably present in the solution were screened by adding $4 \times 10^{-5}$ moles per litre of disodium - othylenediamin - tetraacetic acid (EDTA $)^{3}$. The middle curve shows that less than $2 \times 10^{-7}$ moles per litre of copper ions, accidentally present due to contemination of the surface of the particles and the distilled water, has a significant effect on the reaction rate. The third run was carried out in the presence of $10^{-5}$ moles per litre of cupric chloride. The inhibition was now so strong that the reaction gave the appearance of approaching a new equilibrium concentration, $20-30 \%$ below the real one.

With the object of investigating whether the bulk of the added copper ions was adsorbed on the calcite surface or remained dissolved in the water, the following experiment was carried out: Initially, the liquid contained $10^{-5}$ moles per litre of cupric chloride, but when the concentration of calcium bicarbonate reached $c_{1}$ in Fig. 1, the experiment was stopped, the liquid decanted and used for another run with a fresh portion of calcite. The concentration then continued to rise along the lower curve. At $c_{2}$ this experiment was stopped, the solution removed by decantation and 
a new experiment started with the same particles but with fresh water. The reaction now followed the middle curve. These experiments strongly indicate that the copper was present mainly in the bulk of the liquid and that very little could have been adsorbed at the surface of the particles.

The inhibition by copper ions provides a reasonable explanation for the difficulties encountered by many investigators in reaching a final state of equilibrium. Frear and Johnston found it necessary to allow weeks and Shtermina and Frolova ${ }^{5}$ even months for the establishment of equilibrium. It is shown here that this excessive delay can be eliminated by additions of small quantities of EDTA, an expedient which might prove useful also in other cases involving solid calcium carbonate.

In Fig. 2, the rate of reaction is plotted against the concentration of calcium bicarbonate for partial pressures of carbon dioxide of $0.952,0.664,0.392$ and 0.135 atm. The amount and size of the calcite particles were exactly as for the runs shown in Fig. 1, and $4 \times 10^{-5}$ moles per litre of EDTA was added. Except for a short period after the start of the experiments, the relation between the concentration of calcium bicarbonate and the rate of reaction is linear. Furthermore, the points of intersection of these lines with the abscisse, give the respective equilibrium concentrations. These are 6.2 to $9.8 \%$ lower than

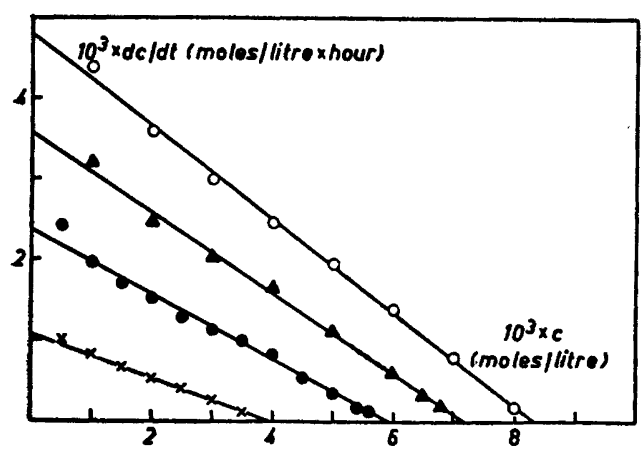

Fig. 2. A plot of the rate of the unhibited reaction against concentration of calcium bicarbonate for different partial pressures of carbon dioxide.

$$
\begin{aligned}
& \text { O: } \mathrm{pCO}_{2}=0.952 \text { atm } \\
& \text { A: } \mathrm{pCO}_{2}=0.664 \\
& \text { } \mathrm{pCO}_{2}=0.392 \\
& \mathrm{x}: \mathrm{pCO}_{2}=0.135
\end{aligned}
$$

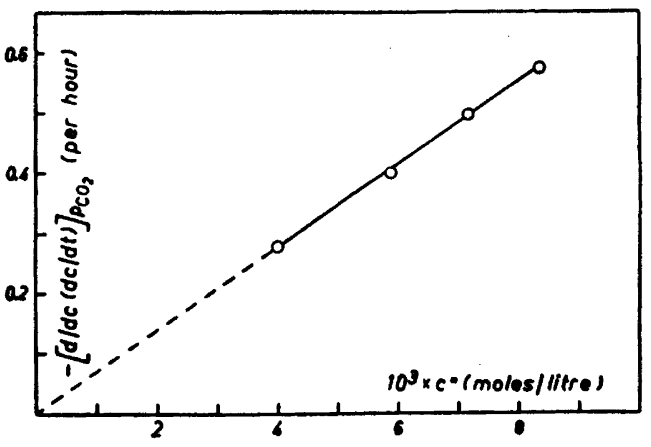

Fig. 3. A plot of the slope of the rate-concentration lines of Fig. 2 against the respective equilibrium concentrations.

the values reported by Frear and Johnston ", who used finely powdered material, but 4 to $0 \%$ higher than those of Miller ${ }^{1}$, obtained with coarser crystalline aggregates of natural calcite.

The slope of the lines in Fig. 2 have been plotted against the corresponding equilibrium concentrations in Fig. 3, and it can be seen that the relationship is a straight line through origo. This means that the results of the experiments without inhibition can be described by the following kinetic equation:

$$
\frac{\mathrm{d} c}{\mathrm{~d} t}=k \cdot c^{*}\left(c^{*}-c\right)
$$

where $c^{*}=$ concentration of calciumbicarbonate at equilibrium in moles per litre; $c=$ concentration of calciumbicarbonate at a time $t$ after start of the reaction; $k=a$ constant, independent of $c^{*}$, but shown below to be proportional to the surface area of the particles per unit volume of suspension.

In an attempt to localise the rate determining steps, experiments were carried out with various gas velocities, intensities of agitation and quantities of particles, but with the same particle size as above and with a partial pressure of carbon dioxide of $0.95-0.97 \mathrm{~atm}$. The rate of reaction was found to be strictly proportional to the surface area of the particles, but independent of the gas velocity in the range investigated. This shows that the rate of reaction is affected neither by the transfer of carbon dioxide from the gas to the liquid, nor by any chemical reaction in the bulk

Acta Chem. Scand. 10 (1956) No. 5 
of the liquid. Consequently, the rate determining steps are localised at the solidliquid interface or in the liquid film in immediate contect with it.

The effect of the rate of stirring can be expressed by the coefficient of stirring, $a$, defined by the relationship: $\mathrm{d} c / \mathrm{d} t$ proportional to (r.p.m.) ${ }^{a}$. The average value of this coefficient was found to be 0.22 over the range investigated, i. e. $280-555$ r.p.m. This is much smaller than the value of 0.5-1.0 generally reported for heterogeneous processes controlled by diffusion *, indicating that chemical reactions are among the rate determining steps.

Further work is in progress in an endeavour to elucidate the reaction mechanism both in the absence and presence of inhibiting metal ions.

1. Miller, J. P. Am. J. Sci. 250 (1952) 161.

2. Brown, G. G. Unit Operations, John Wiley \& Sons, Inc., New York 1950, p. 21.

3. Schwarzenbach, G. Die Komplexometrische Titration, Ferdinand Enke Verlag, Stuttgart 1955.

4. Frear, G. L. and Johnston, J. J. Am. Chem. Soc. 51 (1929) 2082.

5. Shtermina, E. B. and Frolova, E. V. Doklady Akad. Nauk. SSSR 21 (1952) 271; Chem. Abstracts 48 (1954) 6224 a.

6. Bircumshaw, L. L. and Riddiford, A. C. Quart. Rev. London 6 (1952) 157.

Received June 9, 1956.

\section{Action of Ionizing Radiation on Insulating Plastics}

L. EHRENBERG and K. G. ZIMMER

Institute for Organic Chemistry and Biochemistry, University, Stockholm, Sweden, and Max-Planck-Institut für physikalische Chemie, Göttingen, Germany

$T^{2}$ he action of ionizing radiation on insulating plastics is of great interest from various points of view, such as (i) the selection of most suitable materials for the construction of measuring equipment, (ii) the elucidation of the mechanism of induced conductivity and also (iii) as a model for the action of radiation on biologically important macromolecules 1,2. By making use of a new experimental method ${ }^{3}$ it has been possible to demonstrate that induced conductivity during beta irradiation (from $\mathrm{Ce}-\mathrm{Pr}-144)$ as well as the so called aftereffects are generally very different when part of the volume only is irradiated (leaving the insulating surface completely untouched by radiation) or when directing the radiation on the insulating surface *. From a theoretical point of view volume effects seem more interesting but for practical purposes surface effects are sometimes very important. They are often so pronounced as to make an otherwise excellent insulator practically useless. It seemed of interest, therefore, to investigate these surface effects somewhat further.

Insulating surfaces are in most cases in contact with atmospheric air and we thought it likely that, amongst other things, the deterioration might be caused by oxidation under the action of radiation. Oxidation would be expected to lead to the formation of hydrophilic groups and, consequently, to an increase in wettability. This would tend to decrease the usefulness of any insulator as small changes of temperature will always occur and may, on a wettable surface, enable a continuous and conducting layer of water to be formed: The formation of hydrophilic groups we were able to demonstrate in several ways:

(a) Specimens of insulating plastics were exposed to gamma-radiation from $a$ ${ }^{\circ} \mathrm{Co}$ source of 70 Curies and the contact angle of small drops of $0.1 \mathrm{~N} \mathrm{NaOH}$ measured on freshly machined surfaces. For machining we used a tool carefully washed in benzene and alcohol, for measuring a simple device made from a microscope. The data compiled in Table 1 show a considerable decrease of contact angle (increase in adhesion ${ }^{5}$ ).

(b) The formation of hydrophilic groups can be demonstrated very easily using liquid paraffin which has been shown to undergo much the same change of properties under irradiation as does polyethylen $\theta^{6}$. A drop of a paraffin of standard weight put onto a clean surface of $0.1 \mathrm{~N}$ aqueous $\mathrm{NaOH}$ forms a lens with a well defined diameter ${ }^{7}$ which increases due to increased number of hydrophilic groups as the material is irradiated by ionizing radiation (previous to putting drops onto the aqueous alkali). We used $180 \mathrm{kV}$ X-rays for irradiation in this case. A series of measurements is shown in Fig. 1.

(c) The effect can also be demonstrated in another way, lending itself more easily 